\title{
THE EFFECT OF DIABETES ON THE RELATION OF EPICARDIAL FAT THICKNESS TO THE SEVERITY OF CORONARY ARTERY DISEASE In ACUTE NON-ST ELEVATION MYCARDIAL INFARCTION PATIENTS
}

\author{
Mohamed Wafaie Aboleineen, Waleed Salem El-Awady, Marwa Mohamed Gad, Dina Ali \\ Ahmed Fergany \\ Cardiology department-Zagazig University-Zagazig-Egypt
}

Corresponding Author

Dina Ali Ahmed Fergany 0100122154996

dina.fergany@yahoo.com
Background: there is a strong relationship between epicardial fat thickness and severity of coronary artery disease. The impact of diabetes on severity of coronary artery disease (CAD) is well known. The possible impact of diabetes on the relationship between EFT and severity of CAD was not fully investigated.

Patients and Methods: The study included 52 patients with NSTEMI (mean age: 54.3 \pm 6.7 years). Patients were classified into two groups according to presence of diabetes (diabetic group (24 patients) and non-diabetic group (28 patients)). EFT was measured by transthoracic echocardiography on the right ventricle in individuals having the left lateral decubitus position GENSINI score was used to define the severity of CAD.

Results: Diabetic patients had higher EFT values compared with non-diabetics $(\mathrm{p}<0.05)$. EFT is independently associated with diabetes and GENSINI score in all patients ( $\mathrm{p}<0.05$, for all). When patients were divided into two groups, as diabetic and non-diabetic, the association between EFT and GENSINI score was stronger in diabetic patients compared with non-diabetics $(r=0.6618 ; p<$ 0.001 vs. $r=0.330 ; p=0.04$ ).

Conclusion: Epicardial fat thickness is associated with GENSINI score in both diabetic and non-diabetic patients suffering from NSTEMI. Furthermore, there is a stricter relationship between EFT and GENSINI score in diabetic patients

Key words: Epicardial fat thickness, Diabetes, NSTEMI, Gensini score.

\section{INTRODUCTION}

D iabetes is a very important independent risk factor for the development of coronary artery disease ${ }^{1}$. In addition to accelerated atherosclerosis, multiple dynamic factors related to diabetes not only predispose to acute myocardial infarction but also contribute to post-infarction complications ${ }^{2}$. Epicardial fat tissue is an active tissue that originates from the same embryogenic layer as visceral adipose tissue and contributes to the energy supply of the heart and its surrounding tissues, secretes hormones adiponectin and leptin and is also a local reserve for pro-inflammatory cytokines which is related to obesity, hypertension, insulin resistance and coronary artery disease ${ }^{3}$. Epicardial fat measurement may play a role in the stratification of the cardio-metabolic risk and serve as therapeutic target. Weight loss and anti- inflammatory drugs targeting the fat may modulate epicardial fat. Because epicardial and myocardial tissues share the same coronary arterial supply it is reasonable to hypothesize that improved local vascularization may resume epicardial fat to its physiological role ${ }^{4}$. In our study, we search for the impact of diabetes in the relationship between epicardial fat thickness and severity of coronary artery disease by Gensini score in non-ST elevation myocardial infarction patients.

\section{PATIENTS AND METHODS}

Patients included in our study were 52 patients (27 males and 25 females) with mean age $(54.3 \pm 6.7$ years $)$ admitted to the Emergency at Zagazig University between February 2018 and August 2018. They were diagnosed as acute non ST elevation myocardial infarction (any patient with typical chest pain, a positive troponin-I level $\{$ defined in our clinical laboratory as $>0.01$ 
$\mathrm{ng} / \mathrm{ml}$ \} with ST segment changes on 12-lead electrocardiogram.). Patients, who had coronary lesions with a diameter stenosis of $\geq$ $50 \%$, in vessels of size $\geq 1.5 \mathrm{~mm}$, were included. Patients also underwent transthoracic echocardiography before the coronary angiography.

We exclude all patients with a history of coronary artery disease, heart failure (EF < 50 ), hepatic or renal failure, active or chronic inflammatory or autoimmune diseases, severe arrhythmia and patients with poor image quality in the echocardiographic examination.

After assessment of detailed medical history and a complete physical examination, the baseline characteristics including age, sex, hypertension, T2DM, smoking status, family history of CAD, Waist circumference (was measured down to the $0.1 \mathrm{~cm}$ unit at the midpoint between the lower rib margin and the iliac crest) ${ }^{5}$, and previous medications were recorded for all patients.

Venous blood samples were collected from all participants to measure complete blood picture, Serum creatinine with an autoanalyser and Highly-sensitive cardiac troponin I (hs-cTnI)

Transthoracic echocardiography:

Echocardiographic evaluation was done using the commercially available equipment, the digital ultrasound system (GE) Vivid S6 with a 2- to 3-MHz transducer.

Standard parasternal long-axis and short-axis views from two-dimensional images were done for measurement of EFT on the free wall of the right ventricle while patients will be in left lateral decubitus position.

M-mode, 2- dimensional and Doppler echocardiographic assessment was performed for all patients.

\section{Assessment of the EFT}

EFT obtained by echocardiography is generally determined as (the relatively echolucent space between the outer wall of the myocardium and the visceral layer of pericardium; and is measured perpendicularly on the free wall of the right ventricle at endsystole in three cardiac cycles, the average value of three cardiac cycles from each echocardiographic view was determined)

Angiographic assessment of severity of coronary artery disease by GENSINI SCORE

Coronary angiography was performed by Judkins technique without nitroglycerin using 6-French right and left heart catheters. Coronary lesions leading to a diameter stenosis of $\geq 50 \%$ in vessels of $\geq 1.5 \mathrm{~mm}$ were scored separately. Angiogram was analyzed by two interventional cardiologists who were blinded to clinical status and laboratory measurements. After obtaining images by standard approaches, each angiogram was interpreted by two independent cardiologists. The severity of coronary artery lesions will be scored using a modified Gensini scoring system. STATISTICAL ANALYSIS

Data were coded and entered using $\mathrm{R}$ language (R-studio Version 0.99.484 - (C) 2009-2015) for data analysis. Data are expressed as mean value \pm standard deviation and percentage. Differences in frequency of characteristics were assessed by independent sample student's t-test for continuous variables. While Chi-square statistics used for discrete variables. A two-tailed P-value, 0.05 was considered statistically significant ${ }^{6}$.

\section{RESULTS}

The mean EFT values of diabetes and nondiabetes groups were $6.7 \pm 1.3 \mathrm{~mm}$ and $5.4 \pm$ $1.4 \mathrm{~mm}$, respectively. While the mean GENSINI score values of diabetes and nondiabetes groups were $30.18 \pm 16.09 \mathrm{~mm}$ and $20.75 \pm 13.95 \mathrm{~mm}$, respectively. (Table 1)

EFT is associated with GENSINI score in all patients $(\mathrm{r}=0.53, \mathrm{P}=<0.01)$, in non-diabetic group $(\mathrm{r}=0.33, \mathrm{P}=0.04)$ and diabetic group $(r=0.66, P=0.01)$. 
Table 1 Comparison of various variables between the two groups:

\begin{tabular}{|l|c|c|c|}
\hline variables & Diabetic group & $\begin{array}{l}\text { Non-diabetic } \\
\text { group }\end{array}$ & P value \\
\hline SPB $(\mathrm{mmHg})$ & $138 \pm 17.88$ & $126.67 \pm 14.14$ & 0.26 \\
\hline DPB $(\mathrm{mmHg})$ & $88 \pm 8.37$ & $82.22 \pm 9.17$ & 0.27 \\
\hline Waist circumference $(\mathrm{cm})$ & $108.67 \pm 11.08$ & $101.04 \pm 12.76$ & 0.07 \\
\hline LAD $(\mathrm{mm})$ & $35.25 \pm 3.16$ & $36.36 \pm 5.22$ & 0.38 \\
\hline LVID $(\mathrm{mm})$ & $53.35 \pm 6.38$ & $54.71 \pm 8.23$ & 0.53 \\
\hline EF\% & $57.7 \pm 9.52$ & $56.39 \pm 9.32$ & 0.63 \\
\hline Epicardial fat thickness $(\mathrm{mm})$ & $6.72 \pm 1.36$ & $5.36 \pm 1.42$ & 0.001 \\
\hline Gensini score & $30.18 \pm 16.09$ & $20.75 \pm 13.95$ & 0.04 \\
\hline Hemoglobin gm/dl & $12.81 \pm 1.44$ & $13.48 \pm 1.27$ & 0.15 \\
\hline WBCs $\left(\mathrm{x} 10^{3 / \mu l}\right)$ & $8.4 \pm 2.98$ & $9.76 \pm 2.58$ & 0.16 \\
\hline Troponin & $8.63 \pm 3.35$ & $3.99 \pm 2.60$ & 0.26 \\
\hline Creatinine(mg/dl) & $0.967 \pm 0.3$ & $0.98 \pm 0.27$ & 0.93 \\
\hline Age(years) & $53.32 \pm 6.87$ & $55 \pm 6.62$ & 0.41 \\
\hline Gender(male) & $6(30 \%)$ & $20(71.5 \%)$ & 0.01 \\
\hline Smoking & $5(25 \%)$ & $13(46.5 \%)$ & 0.06 \\
\hline HTN & $15(25 \%)$ & $14(50 \%)$ & 0.06 \\
\hline
\end{tabular}

Table 2 Correlations between Epicardial fat thickness and different variables in all groups:

\begin{tabular}{|c|c|c|}
\hline Variables & R value & P value \\
\hline Gensini Score & 0.5390906 & 0.00007707 \\
\hline Creatinine & 0.1769714 & 0.3871 \\
\hline Troponin & -0.6780229 & 0.09412 \\
\hline EF\% & -0.06990567 & 0.6899 \\
\hline LVID & 0.04198239 & 0.8108 \\
\hline LAD & 0.4751717 & 0.005991 \\
\hline Age & -0.01094413 & 0.9518 \\
\hline Hg & -0.07357301 & 0.73 \\
\hline WBCs & -0.39 & 0.06 \\
\hline Waist circumference & 0.14 & 0.43 \\
\hline
\end{tabular}

Table 3 Correlation of Gensini Score with epicardial fat thickness in non-Diabetic patients:

\begin{tabular}{|c|c|c|c|}
\hline Variable & R-value & P-value & \\
\hline Gensini Score & 0.3303559 & 0.044 & Poor correlation \\
\hline
\end{tabular}

Table 4 Correlation of Gensini Score with epicardial fat thickness in Diabetic patients:

\begin{tabular}{|c|c|c|c|}
\hline Variable & r-value & P-value & \\
\hline Gensini Score & 0.6618399 & 0.00148 & Moderate correlation \\
\hline
\end{tabular}




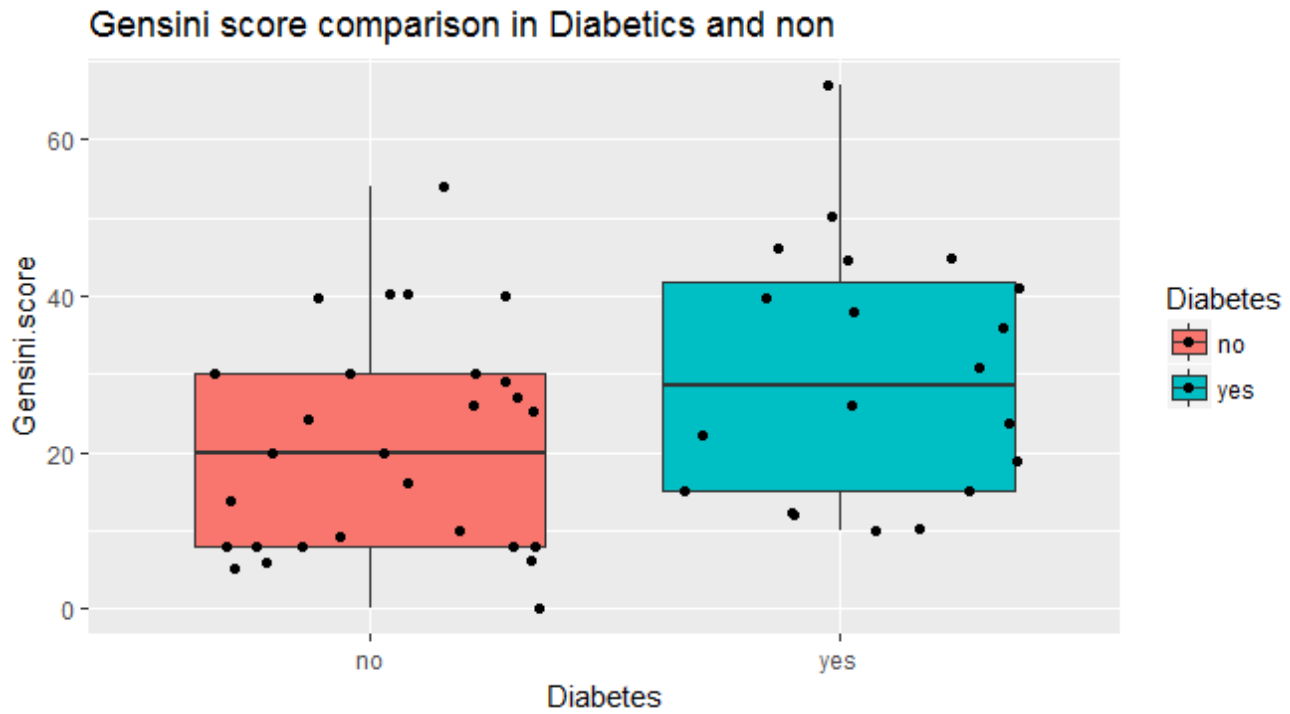

Figure 1 scatter plot diagram shows the comparison between our groups in Gensini score: the difference is statistically significant.

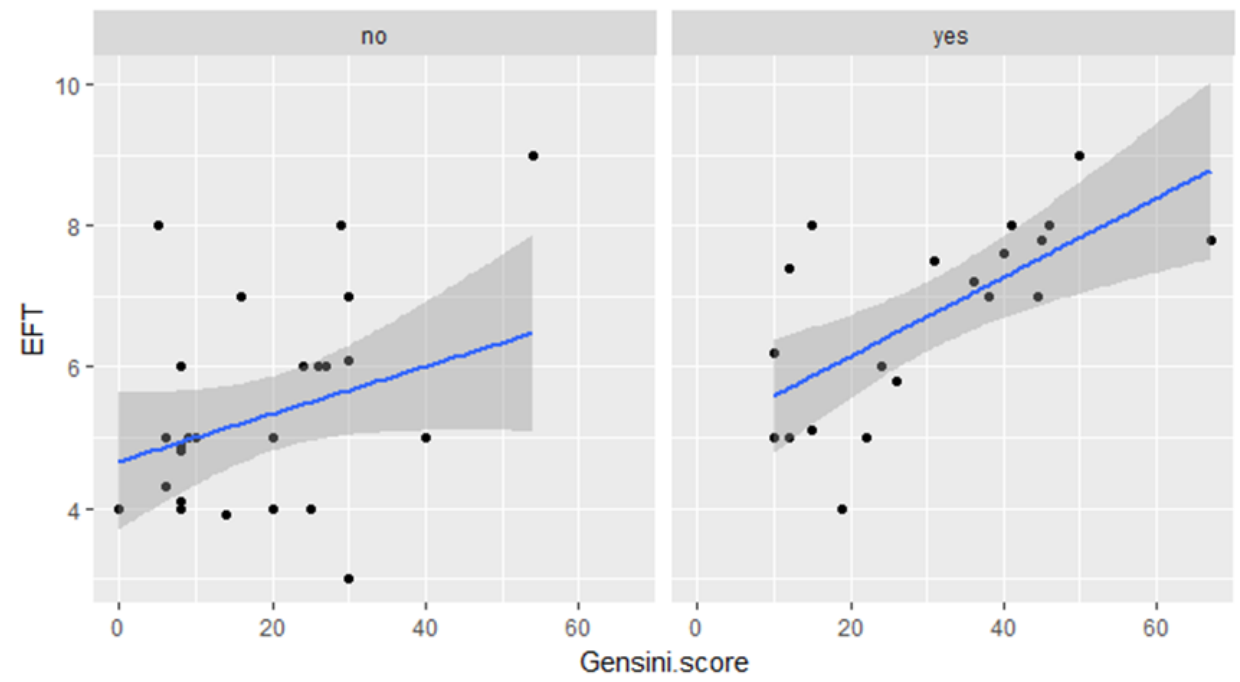

Figure 2 scatter plot with line diagrams shows the correlation between EFT and Gensini score in diabetics and non-diabetic groups. ( $\mathrm{No}=$ Non-diabetic group), (yes=Diabetic group)

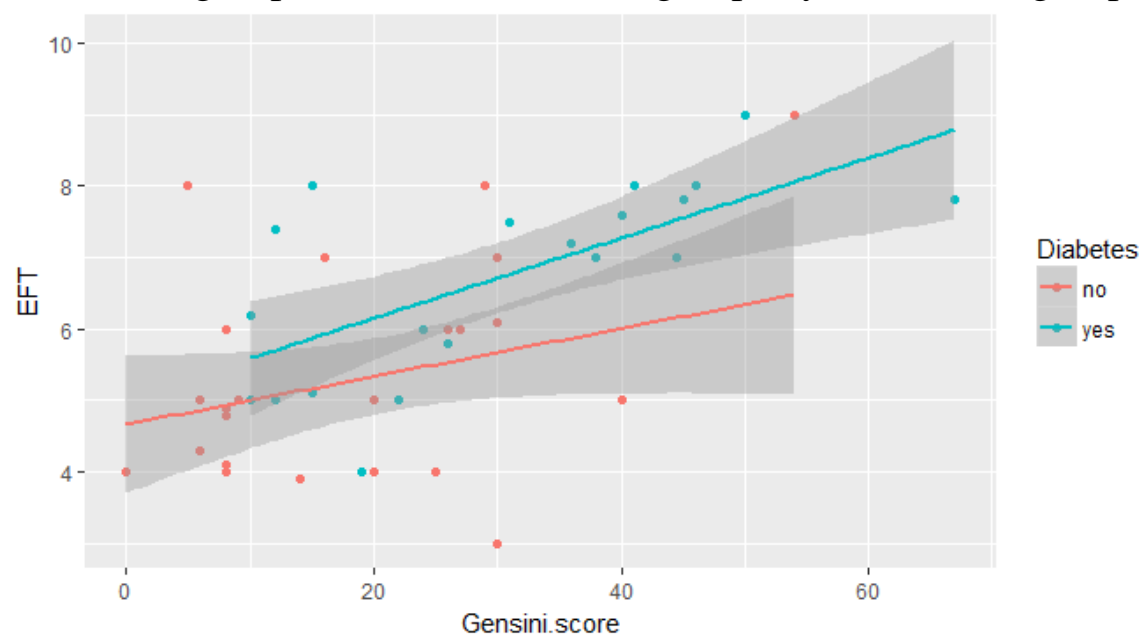

Figure 3 scatter plot with line diagram shows the correlation between EFT and Gensini score in diabetics and non-diabetic groups: the statistically significant positive correlation between EFT and Gensini score in the two groups. 


\section{DISCUSSION}

In our study we found high association between diabetes and Gensini score in non ST elevation myocardial infarction patients with significant correlation ( $\mathrm{p}$ value $<0.05$ ).

This was consistent with saleem et $\mathrm{al}^{7}$. Their study was performed to find the association between glycosylated haemoglobin (HbA1C) level and the severity of coronary artery disease. One hundred and ten consecutive patients admitted to hospital with acute myocardial infarction were studied. They found that there was a significant association between Gensini score and DM ( $\mathrm{p}=0.003)$.

Also, Lekakis et al. ${ }^{8}$ who studied the effects of traditional vascular risk factors such as diabetes on the atherosclerotic changes in the carotid, femoral arteries and on the extent and severity of coronary artery disease (CAD) confirmed this result. They found that diabetes mellitus can be an independent predictor of the extent and severity of CAD.

We found a highly significant positive correlation between EFT and Gensini score (P value $=0.00007707)$ in all our NSTEMI patients.

Our study is strongly in agreement with Eroglu et $\mathrm{al}^{9}$ who found a positive relationship between echocardiographic EAT thickness and severity of coronary artery disease by (Gensini score) in 150 patients. They concluded that EAT thickness, which is easily and non-invasively evaluated by transthoracic echocardiography, can be an adjunctive marker to classical risk factors for the prediction of CAD.

Also, Jeong et $\mathrm{al}^{\mathbf{1 0}}$ found that epicardial fat thickness was significantly correlated with the severity of coronary artery disease in patients with known coronary artery disease. These studies were confirmed by Shemirani and Meysam Khoshavi ${ }^{11}$.

Ahn et $\mathrm{al}^{12}$ measured EAT thickness in 527 patients undergoing their first coronary angiography. The study revealed that patients with unstable angina had thicker EAT compared to those with stable angina or atypical chest pain. These results suggest that the echocardiographic measurement of EAT may provide additional information for assessing CAD risk and predicting the extent and activity of CAD.

On the other hand, our study does not agree with Chaowalit et al ${ }^{13}$ study which concluded that the amount of subepicardial adipose tissue thickness was not associated with the severity of CAD.

Their study was done on older patients (68 \pm 13 years) that can make difference in results. Also there are differences in techniques used in measuring echocardiographic EFT; it was measured at end-diastole and severity of coronary artery disease was assessed by CAGE score while in our study EFT was measured at end-systole and severity of coronary artery disease was assessed by Gensini score.

In our study, we found positive correlation between EFT and severity of coronary artery disease by Gensini score in non-diabetic group ( $\mathrm{P}$ value $=0.08599)$ with more significant correlation in the diabetic group $(\mathrm{P}$ value $=0.00148$ ) .

Sade et $\mathrm{al}^{14}$ indicated that EAT volume by cardiac multi-slice computed tomography is increased in T2DM patients and is associated with unfavorable components of metabolic syndrome and coronary atherosclerosis. The close anatomical relationship between EAT and the coronary arteries, combined with other evidence indicating that EAT is a biologically active adipokine-secreting tissue and participates in the pathogenesis of diabetic coronary atherosclerosis.

\section{CONCLUSION}

Epicardial fat thickness may be associated with the severity of CAD in both diabetic and non-diabetic non ST elevation myocardial infarction patients. However, there is a stricter relationship between EFT and the severity of $\mathrm{CAD}$ in diabetic patients.

\section{REFERENCES}

1. Fein F. Heart disease in diabetes mellitus: theory and practice. Diabetes Mellit theory Pract. 1990;812-23.

2. Heusch G, Libby P, Gersh B, Yellon D, Böhm M, Lopaschuk G, et al. Cardiovascular remodelling in coronary artery disease and heart failure. Lancet. 2014;383(9932):193343.

3. Nar G, Inci S, Aksan G, Unal OK, Nar R, Soylu K. The relationship between epicardial fat thickness and gestational diabetes 
mellitus. Diabetol Metab Syndr. 2014;6(1):120.

4. Iacobellis G. Epicardial fat: a new cardiovascular therapeutic target. Curr Opin Pharmacol. 2016;27:13-8.

5. Nematy M, Alinezhad-Namaghi M, Rashed MM, Mozhdehifard M, Sajjadi SS, Akhlaghi $S$, et al. Effects of Ramadan fasting on cardiovascular risk factors: a prospective observational study. Nutr J. 2012;11(1):69.

6. Halsey LG, Curran-Everett D, Vowler SL, Drummond GB. The fickle $\mathrm{P}$ value generates irreproducible results. Nat Methods. 2015;12(3): 179.

7. Saleem T, Mohammad KH, Abdel-Fattah MM, Abbasi AH. Association of glycosylated haemoglobin level and diabetes mellitus duration with the severity of coronary artery disease. Diabetes Vasc Dis Res. 2008;5(3):184-9.

8. Lekakis JP, Papamichael CM, Cimponeriu AT, Stamatelopoulos KS, Papaioannou TG, Kanakakis J, et al. Atherosclerotic changes of extracoronary arteries are associated with the extent of coronary atherosclerosis. Am J Cardiol. 2000;85(8):949-52.

9. Eroglu S, Sade LE, Yildirir A, Bal U, Ozbicer S, Ozgul AS, et al. Epicardial adipose tissue thickness by echocardiography is a marker for the presence and severity of coronary artery disease. Nutr Metab Cardiovasc Dis. 2009;19(3):211-7.

10. Jeong J-W, Jeong MH, Yun KH, Oh SK, Park EM, Kim YK, et al. Echocardiographic epicardial fat thickness and coronary artery disease. Circ J [Internet]. 2007;71(4):536-9. Available from: http://www.ncbi.nlm.nih.gov/pubmed/17384 455

11. Shemirani H, Meysam Khoshavi M. Correlation of echocardiographic epicardial fat thickness with severity of coronary artery disease-an observational study. Anatol J Cardiol Kardiyol Derg. 2012;12(3).

12. Ahn S-G, Lim H-S, Joe D-Y, Kang S-J, Choi B-J, Choi S-Y, et al. Relationship of epicardial adipose tissue by echocardiography to coronary artery disease. Heart. 2008;94(3):e7-e7.

13. Chaowalit N, Somers VK, Pellikka PA, Rihal CS, Lopez-Jimenez F. Subepicardial adipose tissue and the presence and severity of coronary artery disease. Atherosclerosis. 2006;186(2):354-9.

14. Sade LE, Eroglu S, Bozbaş H, Özbiçer S, Hayran M, Haberal A, et al. Relation between epicardial fat thickness and coronary flow reserve in women with chest pain and angiographically normal coronary arteries. Atherosclerosis. 2009;204(2):580-5.

How to cite this article: Aboleineen WM, El-Awady WS, Gad MM, Fergany DAA. The Effect of Diabetes on The Relation of Epicardial Fat Thickness to The Severity of Coronary Artery Disease in Acute Non- St Elevation Mycardial Infarction Patients. ZUMJ 2019; 25 (1); 149-154. 